\title{
Fitonematóides associados à rizosfera e raízes da mandioca cultivada em rotação com inhame cultivar da Costa
}

\author{
M arlon da Silva Garridoํㅣㄹ J oão L uiz Coimbra², A na Cristina Fermino Soares ${ }^{3}$, Nailson Santos deA Imeida $\&$ Carla da \\ Silva Sousa ${ }^{3}$
}

${ }^{1}$ U niversidade Federal de Pernambuco, Depto. de Energia Nuclear, Laboratório de Fertilidade do Solo, 50.740-540, Recife, PE. garridoms@yahoo.com.br; ²UNE B,D epto. de Ciências Humanas - UNEB, Campus IX, Barreiras, BA .; ${ }^{3}$ U niversidade F ederal do Recôncavo da B ahia (UFRB), Centro de Ciências A grárias, A mbientais e B iológicas, Campus de Cruz das A Imas, Cruz das A Imas, BA.

A utor para correspondência: M arlon da Silva Garrido

Data de chegada: 15/08/2006. A ceito para publicação em: 12/09/2007

1393

\section{RESUMO}

Garrido, M . da S.; Coimbra, J . L.; Soares, A . C. F.; A Imeida, N . S. de \& Sousa, C. da S. Fitonematóides associados à rizosfera e raízes da mandioca cultivadas em rotação com inhame cultivar da Costa. Summa P hytopathologica, v.34, n.2, p.181-182, 2008

O trabalho teve o objetivo de avaliar as populações de fitonematóides associados à cultura da mandioca, plantada em sucessão à cultura do inhame, em 22 propriedades rurais do Recôncavo da Bahia. Adicionalmente, foram feitos testes de hospedabilidade com as variedades de mandioca 'Cigana' e 'Talo Roxo', ao nematóide Scutellonema bradys. Foram constatadas as presenças dos seguintes nematóides: Pratylenchus brachyurus,
Scutellonema bradys, Meloidogyne incognita e Rotylenchulus reniformis, nas raízes e amostras de solo. Além dos nematóides, Tylenchus sp., Aphelenchus sp., Meloidogyne incognita, Mesocriconema sp., Aphelenchoides sp., Helicotylenchus presente apenas nas amostras de solos. 0 teste de hospedabilidade demostrou que as variedades de mandioca estudadas não são hospedeiras de Scutellonema bradys.

Palavras-chave: Casca-Preta, Pratilencose, D ioscorea cayennensis, M anihot esculenta

\section{ABSTRACT}

Garrido, M .da S.; Coimbra, J . L.; Soares, A. C. F.; Almeida, N. S. de \& Sousa, C. da S. Nematodes associated with rhizosphere and roots of cassava planted in rotation with yam crops. Summa Phytopathologica, v.34, n.2, p.181-182, 2008

The work had the objective of evaluating the population of plant parasitic nematodes associated with the cassava crop planted in succession to the yam crop was evaluated in 22 farming in the Recôncavo region of Bahia. A dditionally, the hospitability of two cassava varieties 'Cigana' and 'Talo Roxo' to Scutellonema bradys. The following nematodes were found in cassava roots and soils: Pratylenchus brachyurus, Scutellonema bradys, Meloidogyne incognita, and Rotylenchulus reniformis, Tylenchus sp., Aphelenchus sp., Mesocriconema sp., Aphelenchoides sp., Helicotylenchus. Host status test show that the studied varieties are not hostesses of nematode Scutellonema bradys.

Additional keywords: dry rot, root lesions, Dioscorea cayennensis, M anihot esculenta

U ma prática comum entre os produtores de inhame da Costa (D ioscorea cayennensis Lam.) na região do Recôncavo da Bahia é o plantio consecutivo da cultura da mandioca ( $M$ anihot esculenta $\mathrm{Crantz}$ ) em sucessão à colheita do inhame. A rotação inhame-mandioca, com 0 plantio da mandioca nas entrelinhas do inhame, no período de aproximadamente dois meses antes da colheita do inhame, sob do ponto de vista econômico o sistema é vantajoso para o pequeno produtor, mas tem implicações fitossanitárias, pois as raízes da mandioca permitem a multiplicação dos nematóides dos gêneros Pratylenchus spp. e Meloidogyne spp. (6). Plantas de mandioca infectadas por fitonematóides apresentam altura reduzida e folhas amareladas com reduções significativas na produtividade (6).
O objetivo do presente trabalho foi avaliar populações de fitonematói des associados à cultura da mandioca, plantada em sucessão à cultura do inhame da Costa e realizar testes de hospedabilidade em variedades de mandioca em relação ao nematóide Scutellonema bradys (Steiner \& Le Hew) Andrássy.

As coletas de raízes de mandioca e solo foram realizadas em 22 propriedades rurais, envolvendo os municípios de M aragogipe, Cruz das A Imas e São Felipe. Em cada propriedade, foram retiradas dez amostras de raízes e solo rizosférico de plantas de mandioca, formandose uma amostra composta. Para a extração dos nematóides, foram utilizadas $10 \mathrm{~g}$ de raízes de cada amostra, onde foi utilizada a técnica do liquidificador al iada à centrifugação, em solução de sacarose mais 
Tabela 1. Incidências de nematóides em solo e raízes de mandioca cultivadas em rotação com a cultura do inhame em diferentes municípios do Estado da Bahia.

\begin{tabular}{|c|c|c|c|c|c|c|c|c|}
\hline Nematóides & \multicolumn{2}{|c|}{ Cruz das A Imas } & \multicolumn{2}{|c|}{ São Felipe } & \multicolumn{2}{|c|}{ M aragojipe } & \multicolumn{2}{|c|}{ Freqüência (\%) } \\
\hline Pratylenchus brachyurus & 28 & 1 & 59 & 3 & 46 & 12 & 68,2 & 27,3 \\
\hline M eloidogyne incognita & - & 1 & - & 1 & 6 & 3 & 9,1 & 18,2 \\
\hline Rotylenchulus reniformis & - & 63 & - & 87 & 20 & 14 & 9,1 & 100,0 \\
\hline Mesocriconema sp. & - & 8 & - & 4 & - & 1 & - & 18,2 \\
\hline Aphelenchoides sp. & - & - & - & - & - & 1 & - & 9,1 \\
\hline Helicotylenchus sp. & - & - & - & - & - & 1 & - & 4,5 \\
\hline
\end{tabular}

* Número de nematóides por $10 \mathrm{~g}$ de raiz, ** Número de nematóides por $100 \mathrm{~cm}^{3}$ de solo.

caolim (1), nas amostras de solo foram utilizadas $100 \mathrm{~cm}^{3}$ utilizandose a técnica da flotação centrífuga em solução de sacarose (3). A identificação dos nematóides ao nível de espécie, foi realizada com auxilio de um micrômetro ocular de fio móvel, acoplado a um microscópio ótico, utilizando-se chaves taxonômicas. Para identificação das espécies do gênero M eloidogyne, foi feita dessecação das gal has para retirada de fêmeas realizando-se cortes para observações microscópicas das configurações perineais de fêmeas maduras.

E m seguida, foi instalado um bioensaio em casa de vegetação para verificar hospedabilidade da mandioca ao nematóide S. bradys. U tilizaram-se as variedades 'Talo roxo' (mandioca mansa) e 'Cigana' (mandioca brava). Foram plantadas manivas com $20 \mathrm{~cm}$ de comprimento, em vasos contendo seis litros de solo esterilizado, com 20 repetições para cada variedade. A pós 30 dias do plantio, o solo em cada vaso foi infestado com uma suspensão contendo 1000 nematóides, sendo quantificada em câmara de Peters, com o auxílio do microscópio de objetiva invertida. Noventa dias após o plantio, as plantas foram colhidas e realizadas as extrações de nematóides do solo e das raízes, utilizando-se as técnicas acima citadas.

Foi observada a incidência dos seguintes nematóides nas raízes de mandioca: Pratylenchus brachyurus (Godfrey) Filipjev \& Steklovem $(68,2 \%)$, S. bradys (31,6\%), M eloidogyne incognita (K ofoid $\&$ W hite) Clitwood $(9,1 \%)$ e Rotylenchulus reniformis L inford \& Oliveira $(9,1 \%)$. $\mathrm{Na}$ rizosfera da mandioca foram encontrados os nematóides $\mathrm{R}$. reniformis (100\%), Tylenchus sp. (41\%), Aphelenchus sp. $(63,6 \%)$, M. incognita (18,2\%), S. bradys (31,8\%), M esocriconema sp. $(18,2 \%)$, A phelenchoides sp. (9,1\%), H elicotylenchus (4,5\%) e P. brachyurus $(27,3 \%)$ (Tabela 1$)$.

$\mathrm{N}$ ematoses causadas por M eloidogyne spp. podem reduzir em até $87 \%$ a produtividade de variedades de mandioca suscetíveis (5). As populações de fitonematóides observadas nas amostras de solos e raízes foram baixas para todas as áreas avaliadas, entretanto, baixas populações, se não manejadas de forma adequada, podem em um curto espaço de tempo, tornar-se numerosas e de difícil controle (4).

A mandioca não é uma boa hospedeira de R. reniformis, contudo, populações elevadas no solo podem ocasionar reduções na produtividade (7). Elevadas populações de R. reniformis associados às raízes de inhame da Costa na região do R ecôncavo da $B$ ahia foram observadas por Garrido et al. (2).

0 nematóide $P$. brachyurus é considerado um dos principais nematóides que atacam os plantios de mandioca no mundo (6). A ocorrência de variedades de mandioca resistentes a $\mathrm{P}$ ratylenchus spp. não é relatada pela literatura.

0 parasitismo do nematóide $\mathrm{S}$. bradys é relatado em plantios de mandi oca na N igéria eno Tongo (7). 0 teste de hospedabilidade realizado neste trabal ho demonstrou que as variedades 'Cigana' e 'Talo Roxo' não são hospedeiras de S. bradys. Possivelmente, a hospedabilidade da mandioca a S. bradys depende da variedade avaliada.

\section{REFERÊNCIASBIBLIOGRÁFICAS}

1. Coolen, W.A; D'Herde, C.J. A method for the quantitative extraction of nematodes from plant tissue. Ghent, State A gricultural Research Centre, 1972, 77p.

2. Garrido, M. da S; Coimbra, J. L.; Soares, A. C. F.; Almeida, N. S. de; Perez, J. 0. Levantamento de fitonematóides na cultura do inhame (Dioscorea cayennensis) nas regiões agrícolas do Recôncavo. Nematologia Brasileira, B rasília, v.28, n. 2, p.219-221, 2004.

3. Jenkins, W.R.A.. A rapid centrifugal-flotation technique for separating nematodes from soil. Plant Disease Report, Beltsville, v.48, p.692, 1964.

4. Kwoseh, C.; Plowright, R. A .; Bridge, J. The yam nematode: Scutellonema bradys. In: Sarr, J. L.;Cook, R.; Bridge, J. (ed). Resistence to parasitic nematode. Wallingford, CABI, 2002. v.1, p. 221-228.

5. Makumbi-Kidza, N. N; Speijer, P. R; Sinkora, R. A. Effects of Meloidogyne incognita on growth and storage-root formation of cassava Manihot esculenta. J ornal of Nematology. Lawrence, v.32, Supl., n.48, p. 475-477, 2000.

6. Massola JR, N.S.; Bedendo, I. P. Doenças da mandioca (M anihot esculenta Crantz). In: Kimati, $H$. et al. (ed.). M anual de fitopatologia. 3 ed. São Paulo. Editora Ceres, 1997 v.2, p. 501-510.

7. M cSorley, R; O'Hair, S. K; Parrado, J. L. Nematodes of cassava, Manihot esculenta Crantz. Nematropica. Florida, v.13, n.2, p.261-287, 1983. 